\title{
THE IMPORTANCE OF ELECTRON TRANSFER MECHANISM IN REACTIONS OF NEUTRAL TRANSITION METAL ATOMS
}

\author{
KENJI HONMA and DAVID E. CLEMMER* \\ Department of Material Science, Himeji Institute of Technology, 1479-1 Kanaji, \\ Kamigori, Hyogo, 678-12 Japan \\ *Present address: Department of Chemistry, Northwestern University, Evanston, \\ Illinois
}

(Received 8 April, 1994)

Reaction kinetics of ground, $\mathrm{Ti}\left(\mathrm{a}^{3} \mathrm{~F}\right)$ and $\mathrm{V}\left(\mathrm{a}^{4} \mathrm{~F}\right)$, and excited, $\mathrm{Ti}\left(\mathrm{a}^{5} \mathrm{~F}\right)$ and $\mathrm{V}\left(\mathrm{a}^{6} \mathrm{D}\right)$, states atoms with some simple molecules have been studied by a discharge-flow tube technique. Laser-induced fluorescence (LIF) was used to determine the concentration of the metal atoms as a function of the flow rate of the reactant molecule to obtain effective bimolecular rate constants. The rate constants of reactions with OX $\left(\mathrm{X}=\mathrm{O}, \mathrm{N}, \mathrm{N}_{2}\right.$ ) and $\mathrm{H}_{2} \mathrm{~S}$ show strong inverse correlation with effective ionization potentials (I.P.- $\mathrm{E}_{\mathrm{el}}$, where I.P. and $\mathrm{E}_{\mathrm{el}}$ are ionization potential and electronic energy of metal atom) of the metal atoms. This result suggests that the electron transfer mechanism plays an important role in these reactions. The large rate constants for electronic excited states can be explained by the crossing between ionic and flat neutral potential energy surfaces. The inefficient reaction rates measured for ground states can be explained by the repulsive nature of $4 \mathrm{~s}^{2}$ configuration which can result in a potential barrier.

KEY WORDS: Transition metal, Ti, V, Electron transfer, State selected reaction rate constant.

\section{INTRODUCTION}

Transition metals play a key role in various chemical processes. These systems have been a dominant feature of inorganic and organometallic chemistry and important in various kinds of homogeneous and heterogeneous catalytic processes. Gas phase kinetics of metal atoms and ions provides basic information that is useful for understanding more complex processes like catalysis. For this reason, a large number of studies have been carried out in kinetics of transition metal cations with simple molecules ${ }^{1}$ and recently, the reactions of transition metal atoms have also received considerable attention..$^{2-16}$ However, relatively little is known about the reactions of neutral atoms compared with cations. 
One interesting property of the first row transition metal atoms is the presence of low-lying electronic states that results from the near degeneracy of $4 \mathrm{~s}$ and $3 \mathrm{~d}$ orbitals. This situation provides unique opportunity to study roles of electronic energies and configuration on reactivities. Very recently, the electronic state selective reaction rates have been determined for ground and the first excited states of $\mathrm{Ti}^{17}$ and $\mathrm{V} .7,18$ In all of reaction systems studied so far for both metal atoms, very large enhancements of the reaction rate have been observed by the excitation from the ground state having $4 s^{2} 3 d^{n-2}$ configuration to the excited states having $4 s^{1} 3 d^{n-1}$ configuration ( $n=4$ for Ti and $n=5$ for $\mathrm{V}$ ). There have been two explanations for the difference in reactivities of electronic states.

One explanation is based on the orbital correlation of the reactants and products. In the reactions with oxidants such as $\mathrm{NO}, \mathrm{O}_{2}$ and $\mathrm{N}_{2} \mathrm{O},{ }^{5,7,17}$ metal oxides (MO) are clearly the major reaction products. According to $a b$ initio studies, ${ }^{19,20}$ low-lying electronic states of MO do not correlate with $\mathrm{M}\left(4 \mathrm{~s}^{2} 3 \mathrm{~d}^{\mathrm{n}-2}\right)+\mathrm{OX}$ but do correlate with $M^{*}\left(4 s^{1} 3 d^{n-1}\right)+O X$. Therefore, the metal atom in its ground state needs a potential crossing to react with oxidants and this crossing between repulsive curve from $\mathrm{M}\left(4 \mathrm{~s}^{2} 3 \mathrm{~d}^{\mathrm{n}-2}\right)+\mathrm{OX}$ and reactive curve to $\mathrm{MO}+\mathrm{X}$ causes a potential barrier. Because of this energy barrier and inefficiency of intersystem crossing from low spin surface to high spin surface, the reaction of the ground state should be very inefficient. On the other hand, the electronic excited states having $4 \mathrm{~s}^{1} 3 \mathrm{~d}^{\mathrm{n}-1}$ configuration correlate directly with the ground state of MO, and reaction can proceed directly. This explanation is consistent with the large enhancement of the reaction rates of excited states compared with ground states. However, this model predicts that the reaction rates should increase for metal systems where the $4 s^{1} 3 d^{n-1}$ excited state energy is small. This prediction is not observed experimentally for the reactions of $\mathrm{Sc}, \mathrm{Ti}$, and $\mathrm{V}$ with $\mathrm{NO}, \mathrm{O}_{2}$, and $\mathrm{N}_{2} \mathrm{O}$, casting doubt on this mechanism. ${ }^{5}$

Another proposed reaction mechanism is the electron transfer mechanism. In this mechanism, the reaction rate is determined by the crossing between ionic and covalent potential curves, and the intermolecular distance at the corssing point is predicted by the following equation. ${ }^{21}$

$$
\mathrm{R}_{\mathrm{x}}=\mathrm{e}^{2} /\left\{\mathrm{IP}(\mathrm{M})-\mathrm{EA}(\mathrm{R})-\mathrm{E}_{\mathrm{el}}(\mathrm{M})\right\}
$$

In this equation, $\mathrm{IP}(\mathrm{M}), \mathrm{EA}(\mathrm{R})$, and $\mathrm{E}_{\mathrm{el}}(\mathrm{M})$ are ionization potential of metal atom, electron affinity of neutral molecule, and electronic energy of metal atom, respectively. It can be shown by eq (1) that the rate constants increase as the ionization potential of metal atom decreases. Among the ground states of the three atoms, Sc, $\mathrm{Ti}, \mathrm{V}$, the order of the reaction rates are consistent with the order of the ionization potentials. However, the weak point of this model is inability to explain the order of rate constants among different oxidants (i.e. in spite of its lower electron affinity, NO was observed to have larger rate constant than $\mathrm{O}_{2}$ ).

In this paper, we present reaction rate constants for $\mathrm{Ti}$ and $\mathrm{V}$ in their ground and the first electronic excited states with some oxidants and simple molecules. This is an extension of our previous studies ${ }^{17,18}$ and provides more extensive comparison of the rate constants with two models to clarify the reaction mechanism. 


\section{EXPERIMENTAL}

Experiments were carried out by using a discharge-flow apparatus which was described in detail previously. ${ }^{17}$ Briefly, metal atoms were formed by a DC discharge ( $2.5 \mathrm{kV}$ typically) where a $0.5 \mathrm{~cm}$ dia. transition metal rod (Nilaco, $99.5 \%)$ was used as the cathode. The typical flow rate of $\mathrm{He}$ and pressure of the flow tube were $5000 \mathrm{sccm}$ and 0.7 Torr, respectively. Argon was added to stabilize the discharge. A reactant gas was introduced $\sim 20 \mathrm{~cm}$ downstream from the DC discharge where the flow developed a parabolic profile completely. The concentration of metal atoms was monitored by a laser-induced fluorescence technique at $20.5 \mathrm{~cm}$ downstream from the reactant inlet. The electronic transitions used to detect the metal atoms are summarized in Table 1.

Table I. LIF Transitions used to Probe Ti( $\left.\mathrm{a}^{3} \mathrm{~F}\right), \mathrm{Ti}\left(\mathrm{a}^{5} \mathrm{~F}\right), \mathrm{V}\left(\mathrm{a}^{4} \mathrm{~F}\right) \mathrm{V}\left(\mathrm{a}^{6} \mathrm{D}\right)^{\mathrm{a}}$

\begin{tabular}{|c|c|c|c|}
\hline Species & Transition & Energy, $\mathrm{cm}^{-1}$ & Wavelength $(\mathrm{nm})$ \\
\hline \multirow[t]{3}{*}{$\operatorname{Ti}\left(\mathrm{a}^{3} \mathrm{~F}\right)$} & $y^{3} F_{2}-a^{3} F_{2}$ & $25,107.417$ & 398.29 \\
\hline & $\mathrm{y}^{3} \mathrm{~F}_{3}-\mathrm{a}^{3} \mathrm{~F}_{3}$ & $25,057.085$ & 399.09 \\
\hline & $y^{3} F_{4}-a^{3} F_{4}^{3}$ & $25,001.460$ & 399.98 \\
\hline \multirow[t]{5}{*}{$\mathrm{Ti}\left(\mathrm{a}^{5} \mathrm{~F}\right)$} & $x^{5} D_{0}-a^{5} F_{1}^{4}$ & $23,272.269$ & 429.70 \\
\hline & $x^{3} D_{1}-a^{5} F_{2}$ & $23,256.499$ & 429.99 \\
\hline & $\mathrm{x}^{3} \mathrm{D}_{2}-\mathrm{a}^{5} \mathrm{~F}_{3}$ & $23,246.270$ & 430.18 \\
\hline & $\mathrm{x}^{3} \mathrm{D}_{3}-\mathrm{a}^{5} \mathrm{~F}_{4}^{3}$ & $23,243.428$ & 430.23 \\
\hline & $\mathrm{x}^{3} \mathrm{D}_{4}-\mathrm{a}^{5} \mathrm{~F}_{5}$ & $23,217.364$ & 430.71 \\
\hline \multirow[t]{4}{*}{$\mathrm{V}\left(\mathrm{a}^{4} \mathrm{~F}\right)$} & $y^{4} F_{3 / 2}^{4}-a^{4} F_{3 / 2}$ & $25,930.55$ & 385.65 \\
\hline & $y^{4} F_{5 / 2}-a^{4} F_{5 / 2}$ & $25,866.85$ & 386.60 \\
\hline & $y^{4} F_{7 / 2}^{3 / 2}-a^{4} F_{7 / 2}^{3 / 2}$ & $25,798.64$ & 387.62 \\
\hline & $y^{4} F_{9 / 2}-a^{4} F_{9 / 2}$ & $25,618.96$ & 390.34 \\
\hline \multirow[t]{5}{*}{$V\left(a^{6} D\right)$} & $\mathrm{y}^{6} \mathrm{D}_{3 / 2}-\mathrm{a}^{6} \mathrm{D}_{1 / 2}$ & $24,325.36$ & 411.09 \\
\hline & $\mathrm{y}^{6} \mathrm{D}_{5 / 2}-\mathrm{a}^{6} \mathrm{D}_{3 / 2}$ & $24,352.72$ & 410.63 \\
\hline & $y^{6} D_{7 / 2}-a^{6} D_{5 / 2}$ & $24,384.69$ & 410.09 \\
\hline & $y^{6} D_{7 / 2}-a^{6} D_{7 / 2}$ & $24,293.04$ & 411.64 \\
\hline & $y^{6} D_{9 / 2}-a^{6} D_{9 / 2}$ & $24,313.54$ & 411.29 \\
\hline
\end{tabular}

${ }^{a}$ Energies and wavelengths are derived from data in J. Sugar and C. Corliss, J. Phys. Chem. Ref. Data 14, Suppl. No. 2, (1985).

The LIF intensity was measured as a function of the flow rate of the reactant molecule and this data was converted to an effective bimolecular rate constant by eq (2). We have previously shown that contribution to the measured depletion from quenching and termolecular association processes is negligible. However, we still report our data as "effective rate" constants since we cannot rule out these processes entirely.

$$
\operatorname{In}\left[\mathrm{I}\left(n_{\mathrm{R}}\right) / \mathrm{I}_{0}\right]=-k_{\mathrm{rxn}} t_{\mathrm{rxn}} n_{\mathrm{R}}
$$

In eq $(2), \mathrm{I}\left(n_{\mathrm{R}}\right)$ is the LIF intensity at reactant number density of $n_{\mathrm{R}}$ and $\mathrm{I}_{0}$ is the LIF intensity when no reactant gas is present, $k_{\mathrm{r} \times n}$ is the effective bimolecular rate constant, $t_{\mathrm{rxn}}$ is the mean reaction time (2.0 ms as measured previously) ${ }^{22}$ and $n_{\mathrm{R}}$ is the number density of the reactant. 
A frequency doubled output of a titanium-sapphire laser (Continuum TS-60) pumped by a Nd:YAG laser (Continuum NY-82) was used to detect the metal atoms. The intensity of ultraviolet was carefully controlled within linear response region. Total fluorescence was collected by a photomultiplier tube (HAMAMATSU R-928) and amplified signal was fed into a gated integrator (SRS model SR-250). The atomic transitions are sufficiently narrow that when the laser is tuned to a transition, small drifts in the laser frequency lead to large fluctuations in the LIF signal. To avoid this problem in determining the LIF intensity as a function of reactant flow, the laser was tuned over each transition slowly for every reactant flow rate so that the maximum signal was never missed.

$\mathrm{He}(99.9999 \%), \quad \operatorname{Ar}(99.999 \%), \quad \mathrm{O}_{2}(99.999 \%), \quad \mathrm{NO}(99.9 \%), \quad \mathrm{N}_{2} \mathrm{O}(99.999 \%)$, $\mathrm{NH}_{3}(99.99 \%), \mathrm{H}_{2} \mathrm{~S}(99.99 \%)$, and $\mathrm{C}_{2} \mathrm{H}_{4}(99.999 \%)$ were obtained from NIHON SANSO and used without further purification. The total pressure in the flow tube was measured by a capacitance manometer (MKS Baratron, Type 122A).

\section{RESULTS AND DISCUSSION}

Depletion of LIF signal of $\mathrm{V}\left(\mathrm{a}^{4} \mathrm{~F}\right)$ by $\mathrm{O}_{2}$, NO, and $\mathrm{N}_{2} \mathrm{O}$ are summarized in Figure 1. This figure shows semilogarithmic plots of the $\mathrm{I}\left(n_{\mathrm{R}}\right) / \mathrm{I}_{0}$ for flow rate of oxidants from $0-100 \mathrm{sccm}$ at He pressure of 0.7 Torr. The plots of the four $J$ levels are shown in Fig. 2 for the reaction with $\mathrm{O}_{2}$ and they are indistinguishable within experimental accuracy. Rate constants determined from these kinds of plots are $(2.7 \pm 0.2) \times$ $10^{-12} \mathrm{~cm}^{3} \mathrm{~s}^{-1},(9.7 \pm 0.8) \times 10^{-12} \mathrm{~cm}^{3} \mathrm{~s}^{-1}$, and $(0.40 \pm 0.01) \times 10^{-12} \mathrm{~cm}^{3} \mathrm{~s}^{-1}$, for $\mathrm{O}_{2}, \mathrm{NO}$, and $\mathrm{N}_{2} \mathrm{O}$, respectively.

Figure 3 shows the same kind of plots for $\mathrm{V}\left(\mathrm{a}^{6} \mathrm{D}\right)$ for flow rate of oxidants from 0-2 sccm at He pressure of 0.7 Torr. Again the plots for six J levels are indistinguishable within the uncertainty of measurement. These results indicate either that the rates for different $\mathbf{J}$ level are the same or that the reaction rate is much slower than the rates of interconversion among $\mathrm{J}$ levels by collisions with He. ${ }^{23}$ Compared with Figure 1, the depletion of $\mathrm{V}\left(\mathrm{a}^{6} \mathrm{D}\right)$ is much faster, and rate constants determined from these plots are $(113 \pm 4) \times 10^{-12} \mathrm{~cm}^{3} \mathrm{~s}^{-1},(118 \pm 8) \times 10^{-12} \mathrm{~cm}^{3} \mathrm{~s}^{-1}$, and $(83 \pm 7)$ $\times 10^{-12} \mathrm{~cm}^{3} \mathrm{~s}^{-1}$, for $\mathrm{O}_{2}, \mathrm{NO}$, and $\mathrm{N}_{2} \mathrm{O}$, respectively. These rate constants are summarized in Table II.

The rate constants for reactions of $\mathrm{V}\left(\mathrm{a}^{4} \mathrm{~F}\right)$ with same oxidants have been determined by Ritter and Weishaar ${ }^{5}$ and our values are in good agreement with their values at both $\mathrm{He}$ pressures, i.e. 0.4 and 0.8 Torr. The rate constants of $\mathrm{V}\left(\mathrm{a}^{4} \mathrm{~F}\right)$ and $\mathrm{V}\left(\mathrm{a}^{6} \mathrm{D}\right)$ with $\mathrm{O}_{2}$ and $\mathrm{NO}$ have been determined by McClean and Pasternack ${ }^{7}$ at relatively high background pressure, i.e. 21 Torr. Our values are in good agreement with those values and this agreement suggests that these rate constants have no pressure dependence and are entirely bimolecular ones. In Table II, rate constants of other reaction systems we have measured are also listed.

In all reaction systems of metal atoms with oxidants, it is clear that the metal atoms in ground states have small rate constants and those in excited states have much larger rate constants. Interestingly, these rate constants show the same order, 


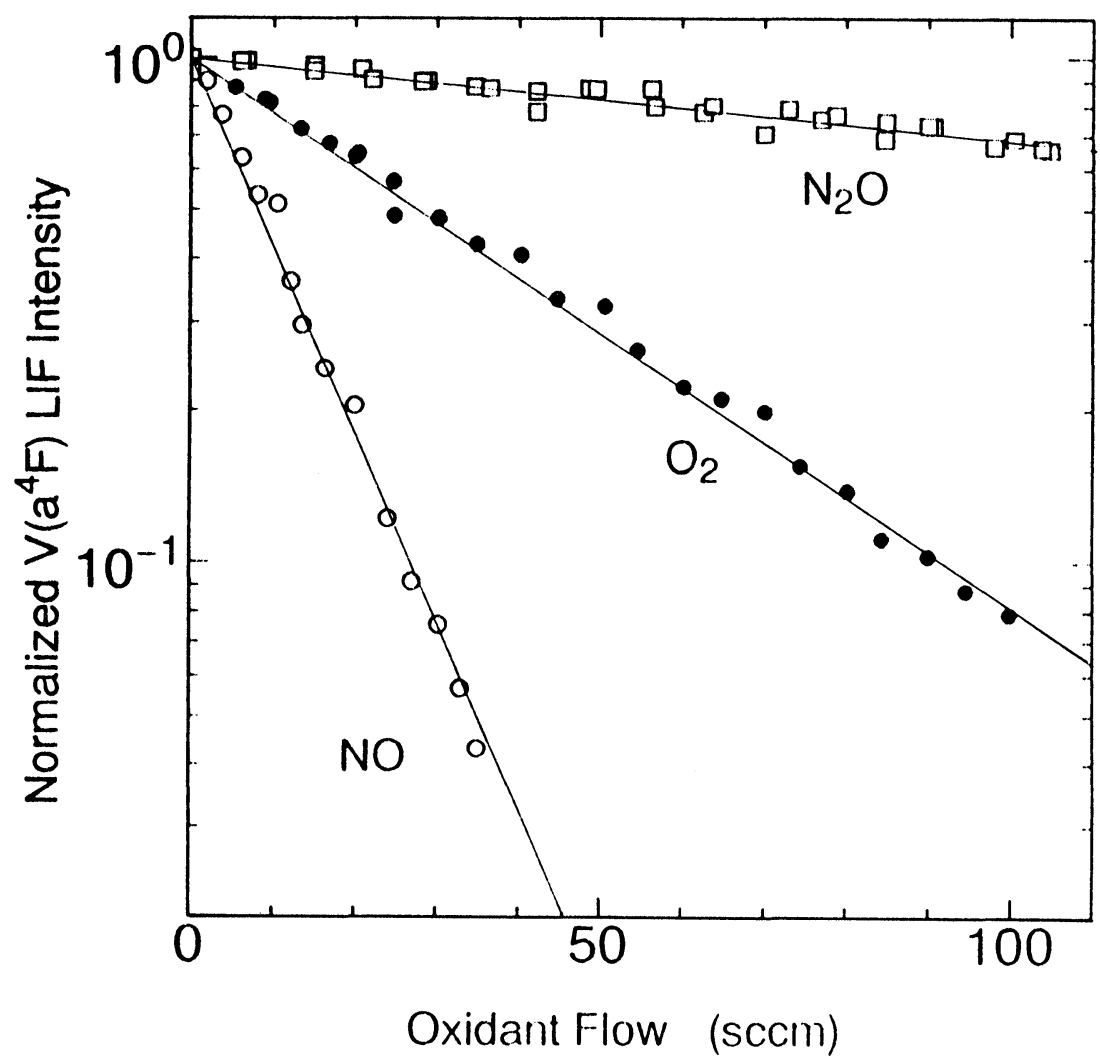

Figure 1 Semilogarithmic plots of the $\mathrm{I}\left(\mathrm{n}_{\mathrm{R}}\right) / \mathrm{I}_{0}$ for $\mathrm{V}\left(\mathrm{a}^{4} \mathrm{~F}\right)$ vs flow of $\mathrm{NO}, \mathrm{O}_{2}$, and $\mathrm{N}_{2} \mathrm{O}$. The solid lines are optimized least-squares fits of eq (2) to the data.

$\mathrm{Ti}\left(\mathrm{a}^{3} \mathrm{~F}\right)+\mathrm{OX}<\mathrm{V}\left(\mathrm{a}^{4} \mathrm{~F}\right)+\mathrm{OX}<\mathrm{V}\left(\mathrm{a}^{6} \mathrm{D}\right)+\mathrm{OX} \mathrm{Ti}\left(\mathrm{a}^{5} \mathrm{~F}\right)+\mathrm{OX}$, for all oxidants. ${ }^{24}$ Among the $\mathrm{H}_{2} \mathrm{~S}, \mathrm{NH}_{3}$ and $\mathrm{C}_{2} \mathrm{H}_{4}$ reactant gases, only $\mathrm{H}_{2} \mathrm{~S}$ can react with ground state metal atoms. The other reactants react only with metal atoms in the electronic excited states, and the rate constants are very large. The order of rate constants with $\mathrm{H}_{2} \mathrm{~S}$ is the same as those of reaction with oxidants, i.e. $\mathrm{Ti}\left(\mathrm{a}^{3} \mathrm{~F}\right)<\mathrm{V}\left(\mathrm{a}^{4} \mathrm{~F}\right)<\mathrm{V}\left(\mathrm{a}^{6} \mathrm{D}\right)<\mathrm{Ti}\left(\mathrm{a}^{5} \mathrm{~F}\right)$. Although $\mathrm{C}_{2} \mathrm{H}_{4}$ does not react with ground state metal atoms, it can react with $\mathrm{Ti}\left(\mathrm{a}^{5} \mathrm{~F}\right)$ or $\mathrm{V}\left(\mathrm{a}^{6} \mathrm{D}\right)$ quite efficiently. The order of rate constants is again $\mathrm{V}\left(\mathrm{a}^{6} \mathrm{D}\right)<\operatorname{Ti}\left(\mathrm{a}^{5} \mathrm{~F}\right)$ which is the same as the reactions of oxidants or $\mathrm{H}_{2} \mathrm{~S}$. Only ammonia has larger rate constant for reaction with $\mathrm{V}\left(\mathrm{a}^{6} \mathrm{D}\right)$ than that for reaction with $\mathrm{Ti}\left(\mathrm{a}^{5} \mathrm{~F}\right)$.

\section{Reaction products}

There is only a little information about products of reactions of neutral transition metal atoms. Among reaction systems summarized in Table II, Ti( $\left.a^{5} \mathrm{~F}\right)+\mathrm{N}_{2}$ and $\mathrm{V}\left(\mathrm{a}^{6} \mathrm{D}\right)+\mathrm{N}_{2}$ are probably the simplest cases. TiN and VN formation are highly endothermic and only electronic quenching of the metal atoms is possible. These 


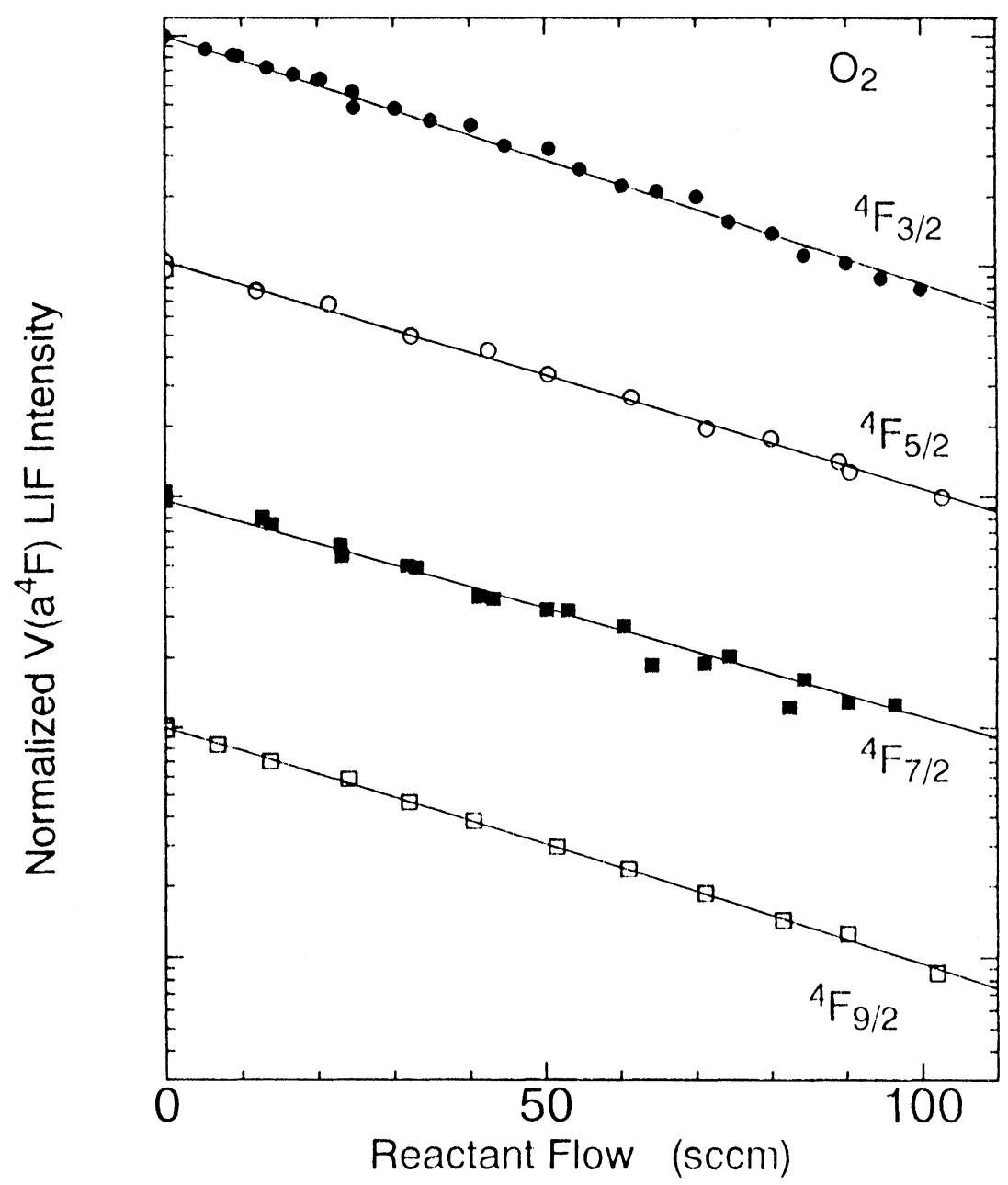

Figure 2 Semilogarithmic plots of the $\mathrm{I}\left(\mathrm{n}_{\mathrm{R}}\right) / \mathrm{I}_{0}$ for the four $\mathrm{J}$ levels of $\mathrm{V}\left(\mathrm{a}^{6} \mathrm{D}\right)$ vs $\mathrm{O}_{2}$. The solid lines are optimized least-squares fits of eq (2) to the data.

rate constants provide estimates for typical quenching rates by nonpolar molecules. Interestingly the rate constant of $\operatorname{Ti}\left(\mathrm{a}^{5} \mathrm{~F}\right)$ is about an order of magnitude larger than that of $\mathrm{V}\left(\mathrm{a}^{6} \mathrm{D}\right)$. In our previous paper, ${ }^{17}$ we discussed the quenching rate of $\mathrm{Ti}\left(\mathrm{a}^{5} \mathrm{~F}\right)$ with $\mathrm{N}_{2}$ by using curve-crossing model of simplified potentials. In this model, only the repulsive interactions are taken into account. Due to the large spacial extent of the closed $4 \mathrm{~s}$ subshell, the surface evolving from $\operatorname{Ti}\left(\mathrm{a}^{3} \mathrm{~F}\right)+\mathrm{N}_{2}$ is expected to be repulsive at longer $\mathrm{Ti}-\mathrm{N}_{2}$ separation than that evolving from $\operatorname{Ti}\left(\mathrm{a}^{5} \mathrm{~F}\right)+\mathrm{N}_{2}$, where the $4 \mathrm{~s}$ orbital is only single occupied. As the $\mathrm{Ti}$ and $\mathrm{N}_{2}$ distance lessens, surfaces evolving from the $\mathrm{a}^{3} \mathrm{~F}$ and $\mathrm{a}^{5} \mathrm{~F}$ state cross. If the system starts from $\mathrm{Ti}\left(\mathrm{a}^{5} \mathrm{~F}\right)+\mathrm{N}_{2}$, one unpaired electron is moved from a $3 \mathrm{~d}$ to $4 \mathrm{~s}$ orbital by spin-orbit interaction at this crossing. If we apply this explanation to $\mathrm{V}+\mathrm{N}_{2}$ system, the $\mathrm{V}-\mathrm{N}_{2}$ separation where the surface 


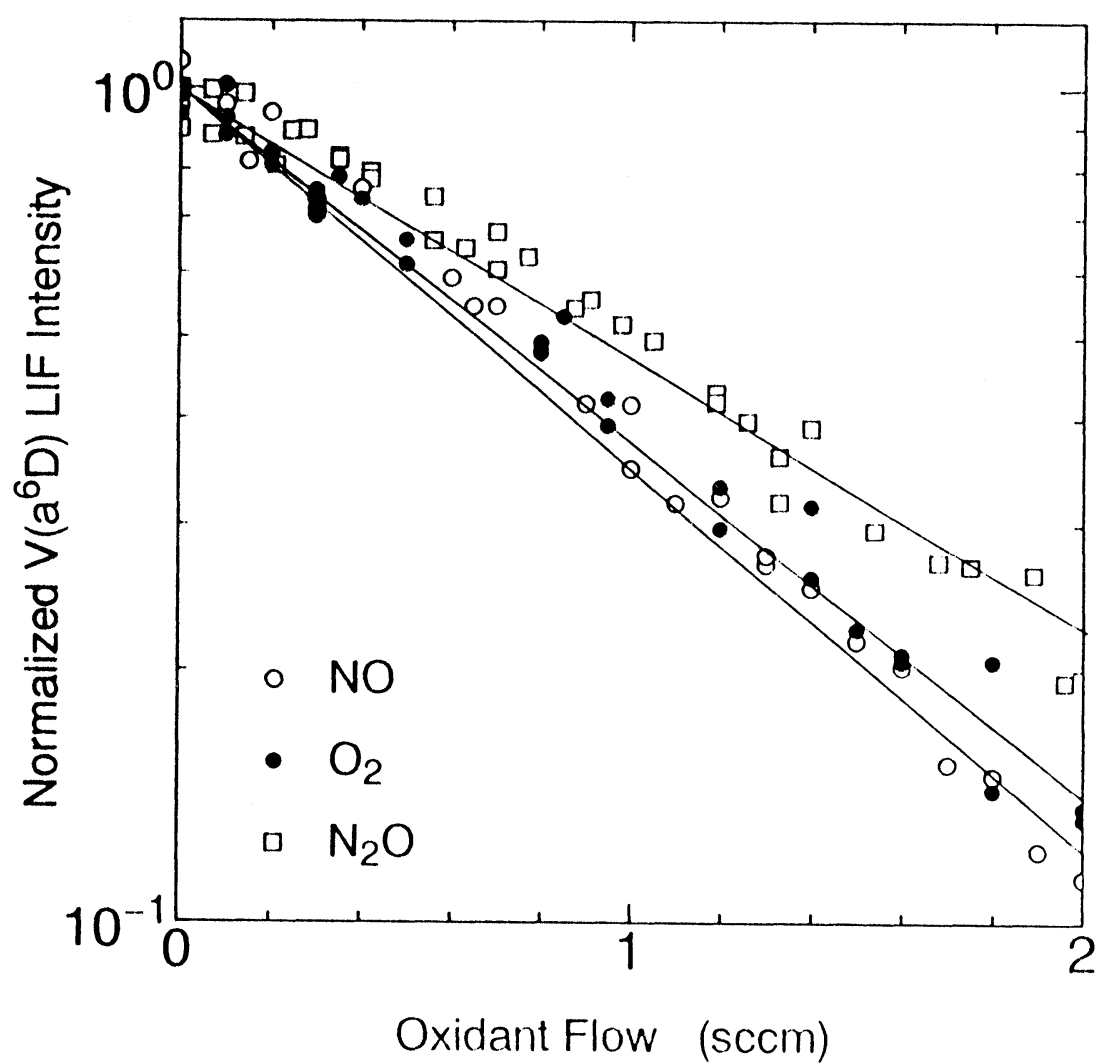

Figure 3 Semilogarithmic plots of the $\mathrm{I}\left(\mathrm{n}_{\mathrm{R}}\right) / \mathrm{I}_{0}$ for $\mathrm{V}\left(\mathrm{a}^{6} \mathrm{D}\right)$ vs flow of $\mathrm{NO}, \mathrm{O}_{2}$, and $\mathrm{N}_{2} \mathrm{O}$. The solid lines are optimized least-squares fits of eq (2) to the data.

crossing occurs must be larger than the Ti- $\mathrm{N}_{2}$ separation and larger rate constant is expected for $\mathrm{V}+\mathrm{N}_{2}$ system, since the electronic excitation energy of $\mathrm{V}\left(\mathrm{a}^{6} \mathrm{D}\right)$ is smaller than that of $\mathrm{Ti}\left(\mathrm{a}^{5} \mathrm{~F}\right)$. Reverse is shown in our experimental results, i.e. $\mathrm{Ti}\left(\mathrm{a}^{5} \mathrm{~F}\right)$ has larger rate constant than $\mathrm{V}\left(\mathrm{a}^{6} \mathrm{D}\right)$. If we assume that our previous potential features are applicable to both systems, one possible explanation for larger rate constant of Ti- $\mathrm{N}_{2}$ is an occurrence of electronic to vibrational (E-V) energy transfer. The excitation energy of $\mathrm{V}\left(\mathrm{a}^{6} \mathrm{D}\right)$ is $1977.4 \mathrm{~cm}^{-1}{ }^{25}$ which is smaller than the vibrational energy of $\mathrm{N}_{2}, 2358.57 \mathrm{~cm}^{-1}{ }^{26}$ Therefore, only $\mathrm{Ti}\left(\mathrm{a}^{5} \mathrm{~F}\right)$ can be quenched by the $\mathrm{E}-\mathrm{V}$ process.

In other reactant systems, rate constants for the electronic excited states of metals are much larger than those of the quenching rate constants by $\mathrm{N}_{2}$. It could be possible that the quenching by polar molecules, $\mathrm{NH}_{3}$ and $\mathrm{H}_{2} \mathrm{~S}$, has larger rate constants because of polar interaction with metal atoms. For polyatomic reactants, $\mathrm{N}_{2} \mathrm{O}, \mathrm{NH}_{3}, \mathrm{H}_{2} \mathrm{~S}$, and $\mathrm{C}_{2} \mathrm{H}_{4}$, also efficient E-V quenching processes may be able to explain the large rate constants for metal atoms in the electronic excited states. However, in the case of the electronic quenching of other metals atoms, $\mathrm{Hg}\left({ }^{1} \mathrm{P}_{1}\right), \mathrm{Cd}\left({ }^{1} \mathrm{P}_{1}\right), \mathrm{Zn}\left({ }^{1} \mathrm{P}_{1}\right)$, and $\mathrm{Mg}\left({ }^{1} \mathrm{P}_{1}\right), \mathrm{NH}_{3}$ and $\mathrm{C}_{2} \mathrm{H}_{4}$ are not very efficient quenchers because of their highly negative electron affinities. ${ }^{27}$ If the quenching is dominant for the systems other than 
Table 2. Effective bimolecular rate constants for reactions of $\operatorname{Ti}\left(\mathrm{a}^{3} \mathrm{~F}\right), \operatorname{Ti}\left(\mathrm{a}^{5} \mathrm{~F}\right), \mathrm{V}\left(\mathrm{a}^{4} \mathrm{~F}\right)$, and $\mathrm{V}\left(\mathrm{a}^{6} \mathrm{D}\right)$ with simple molecules. (in $10^{-12} \mathrm{~cm}^{3} \mathrm{~s}^{-1}$ )

\begin{tabular}{|c|c|c|c|c|c|}
\hline \multirow[t]{2}{*}{ Reactant } & $I P(e V)$ & $\begin{array}{l}\operatorname{Ti}\left(a^{3} F\right) \\
6.82^{a}\end{array}$ & $\begin{array}{l}\text { Til }\left(a^{5} F\right) \\
6.01^{b}\end{array}$ & $\begin{array}{l}V\left(a^{4} F\right) \\
6.74^{a}\end{array}$ & $\begin{array}{l}V\left(a^{6} D\right) \\
6.48^{b}\end{array}$ \\
\hline & \multicolumn{5}{|l|}{$E A(e V)$} \\
\hline NO & $0.024^{c}$ & $\begin{array}{l}7.3 \pm 0.8^{\mathrm{d}} \\
7.8 \pm 0.2^{\mathrm{e}}\end{array}$ & $146 \pm 17^{\mathrm{d}}$ & $\begin{array}{l}9.7 \pm 0.8 \\
8.7 \pm 0.4^{\mathrm{e}} \\
10.9 \pm 1.7^{\mathrm{f}}\end{array}$ & $\begin{array}{l}118 \pm 8 \\
100 \pm 16^{\mathrm{f}}\end{array}$ \\
\hline $\mathrm{O}_{2}$ & $0.440^{\mathrm{c}}$ & $\begin{array}{l}1.6 \pm 0.2^{\mathrm{d}} \\
1.5 \pm 0.2^{\mathrm{e}}\end{array}$ & $135 \pm 29^{d}$ & $\begin{array}{l}2.7 \pm 0.2 \\
2.9 \pm 0.04^{\mathrm{e}} \\
3.26 \pm 0.49^{\mathrm{f}}\end{array}$ & $\begin{array}{l}113 \pm 4 \\
134 \pm 21^{\mathrm{f}}\end{array}$ \\
\hline $\mathrm{N}_{2} \mathrm{O}$ & $-0.2^{\mathrm{g}}$ & $\begin{array}{l}0.7 \pm 0.2^{\mathrm{d}} \\
0.40 \pm 0.05^{\mathrm{e}}\end{array}$ & $>190^{d}$ & $\begin{array}{l}0.40 \pm 0.01 \\
0.45 \pm 0.02^{\mathrm{e}}\end{array}$ & $83 \pm 7$ \\
\hline $\mathrm{N}_{2}$ & $-1.6^{\mathrm{a}}$ & $\mathrm{NR}^{\mathrm{h}}$ & $6.5 \pm 2.2^{\mathrm{d}}$ & $\mathrm{NR}^{\mathrm{h}}$ & $\begin{array}{l}0.50 \pm 0.03 \\
0.562 \pm 0.083^{f}\end{array}$ \\
\hline $\mathrm{H}_{2} \mathrm{~S}$ & $1.11^{\mathrm{a}}$ & $0.44 \pm 0.12^{i}$ & $142 \pm 13^{i}$ & $4.0 \pm 0.2^{i}$ & $69 \pm 5^{i}$ \\
\hline $\mathrm{NH}_{3}$ & & $\mathrm{NR}^{\mathrm{h}}$ & $39 \pm 11^{\mathrm{i}}$ & $\mathrm{NR}^{\mathrm{h}}$ & $95 \pm 8^{i}$ \\
\hline $\mathrm{C}_{2} \mathrm{H}_{4}$ & $-1.78^{\mathrm{j}}$ & $\mathrm{NR}^{\mathrm{h}}$ & $266 \pm 86^{i}$ & $\mathrm{NR}^{\mathrm{h}}$ & $84 \pm 3^{i}$ \\
\hline
\end{tabular}

a H. M. Rosenstock, K. Draxl, B. W. Steiner, and J. T. Herron. J. Phys. Chem. Ref. Data 6 (Suppl. 1) (1977).

b Effective ionization potentials, IP(M)- $E_{\mathrm{el}}$, where $\mathrm{E}_{\mathrm{el}}$, electronic energy of metal atom obtained by averaging the energies of $\mathrm{J}$ levels statistically.

c P. S. Drzaic, J. Marks, and J. I. Brauman, Gas Phase Ion Chemistry, M. T. Bowers Ed. Academic Press, New York, 1984, Vol. 3.

d Ref. 17

e Rate constants determined at 0.8 Torr of He in Ref. 5

f Ref. 7

g S. G. Lias, J. E. Bartmess, J. F. Liebman, J. L. Holmes, R. D. Levin, W. G. Mallard, J. Phys. Chem. Ref. Data, 17, Suppl. (1988).

$\mathrm{h}$ No depletion was observed and this implies that $\mathrm{k} \leq 5 \times 10^{-14} \mathrm{~cm}^{3} \mathrm{~s}^{-1}$.

i Ref. 18

j K. D. Jordan and P. D. Burrow, Acc. Chem. Res. 11, 341 (1978).

$\mathrm{N}_{2}$, it could be possible to detect an increase of the LIF signal of ground state atom with increase of the reactant flow rate since this is formed by the quenching of the excited states. However, no measurement shows such increase of the ground state signal. In case of $\mathrm{V}\left(\mathrm{a}^{6} \mathrm{D}\right)$, the relative population of the excited state can be evaluated to be $11 \%{ }^{28}$ and it must be possible to detect the increase of LIF signal if the physical quenching is dominant process. Therefore, we conclude that the physical quenching is not a major process, especially for the interaction of $\mathrm{V}\left(\mathrm{a}^{6} \mathrm{D}\right)$ with reactants. In the case of $\mathrm{Ti}$, we could not observe any increase of the $\mathrm{Ti}\left(\mathrm{a}^{3} \mathrm{~F}\right)$ signal which must be ascribed to the quenching of $\operatorname{Ti}\left(\mathrm{a}^{5} \mathrm{~F}\right)$. However, it may not rule out the absence of the quenching of $\operatorname{Ti}\left(\mathrm{a}^{5} \mathrm{~F}\right)$ since the relative population of $\operatorname{Ti}\left(\mathrm{a}^{5} \mathrm{~F}\right)$ is smaller than that of $\mathrm{V}\left(\mathrm{a}^{6} \mathrm{D}\right)$.

Another explanation of large depletion rates is that bimolecular reactions occur. These reactions must be dominant in the systems which show the depletion of ground state metal atoms. In the reactions of $\mathrm{Ti}$ and $\mathrm{V}$ with oxides, $\mathrm{O}_{2}, \mathrm{NO}$ and $\mathrm{N}_{2} \mathrm{O}$, the oxidation reactions, $\mathrm{M}+\mathrm{OX} \rightarrow \mathrm{MO}+\mathrm{X}$, are energetically possible. For reactions 
with $\mathrm{O}_{2}$ and $\mathrm{N}_{2} \mathrm{O}$, chemiluminescent studies have observed the formation of electronically excited oxides, $\operatorname{TiO}\left(\mathrm{A}^{3} \Phi, \mathrm{B}^{3} \Pi, \mathrm{C}^{3} \Delta\right.$, and $\left.\mathrm{E}^{3} \Pi\right)$ and $\operatorname{VO}\left(\mathrm{B}^{4} \Pi\right){ }^{9,10}$ These products are also accessible for the electronically excited state of metal atoms. For the ground states of metals, Ritter and Weishaar have detected TiO by LIF in the reaction of Ti with oxidants, $\mathrm{O}_{2}, \mathrm{NO}$, and $\mathrm{N}_{2} \mathrm{O}$. Therefore, it can be concluded that the oxidation in the major process in the $\mathrm{Ti}, \mathrm{V}+\mathrm{OX}$ systems.

As we discussed in the previous paper, ${ }^{18}$ almost no experimental information is available for the reactions of $\mathrm{Ti}$ and $\mathrm{V}$ with $\mathrm{H}_{2} \mathrm{~S}, \mathrm{NH}_{3}$, and $\mathrm{C}_{2} \mathrm{H}_{4}$. One effective way to gain insight into the reaction products is to consider the thermochemistry. Although full thermochemical information is not available for these systems, some possible product channels are derived from these considerations. We have discussed the thermochemistry of these systems in total and concluded that dehydrogenation (reactions (3)-(5)) almost certainly accounts for the depletion of $\mathrm{Ti}$ and $\mathrm{V}$ by $\mathrm{NH}_{3}, \mathrm{H}_{2} \mathrm{~S}$, and $\mathrm{C}_{2} \mathrm{H}_{4} \cdot{ }^{18}$

$$
\begin{gathered}
\mathrm{M}+\mathrm{NH}_{3} \rightarrow \mathrm{MNH}+\mathrm{H}_{2} \\
\mathrm{M}+\mathrm{H}_{2} \mathrm{~S} \rightarrow \mathrm{MS}+\mathrm{H}_{2} \\
\mathrm{M}+\mathrm{C}_{2} \mathrm{H}_{4} \rightarrow \mathrm{MC}_{2} \mathrm{H}_{2}+\mathrm{H}_{2}
\end{gathered}
$$

\section{Reaction mechanism}

The enhancements of the rate constants by electronic excitations can be explained by two reaction mechanisms; atom-abstraction and electron-transfer. In the reactions of $\mathrm{Ti}$ and $\mathrm{V}$ with $\mathrm{NO}, \mathrm{O}_{2}$, and $\mathrm{N}_{2} \mathrm{O}$, the products are metal oxides, whose ground states have $8 \sigma^{2} 3 \pi^{4} 9 \sigma^{1} 1^{\mathrm{x}}$ electron configurations $(\mathrm{x}=1$ and 2 for $\mathrm{TiO}$ and $\mathrm{VO}$, respectively). These electronic states correlate not to $\mathrm{M}\left(4 \mathrm{~s}^{2} 3 \mathrm{~d}^{\mathrm{n}-2}\right)+$ OX reactant pair but to $M\left(4 s^{1} 3 d^{n-1}\right)+O X$. Since the $M\left(4 s^{2} 3 d^{n-2}\right)+O X$ reactants correlate to higher excited states of the metal oxide, the energy barrier arises from the surface crossing between the potential surface evolved from the ground state reactants and the potential surface evolving from the excited state. On the other hand, $\operatorname{Ti}\left(\mathrm{a}^{5} \mathrm{~F}\right)$ or $\mathrm{V}\left(\mathrm{a}^{6} \mathrm{D}\right)+$ OX pair directly correlates with the ground state product and the potential surface evolving from this pair should have no potential barrier, consistent with the high efficiencies of these processes. Similar considerations are applicable for $\mathrm{M}+\mathrm{H}_{2} \mathrm{~S}$, and $\mathrm{M}+\mathrm{NH}_{3}$ if the dehydrogenation is a major process in both systems, since MS and MNH have isoelectronic configuration with MO. This mechanism can explain not only the enhancement of rate constants by the electronic excitation but the order of rate constants between $\mathrm{V}\left(\mathrm{a}^{4} \mathrm{~F}\right)$ and $\operatorname{Ti}\left(\mathrm{a}^{3} \mathrm{~F}\right)$. That is, $\mathrm{V}\left(\mathrm{a}^{4} \mathrm{~F}\right)$ should have larger rate constant than $\operatorname{Ti}\left(\mathrm{a}^{3} \mathrm{~F}\right)$, since higher excitation energy of $\operatorname{Ti}\left(\mathrm{a}^{5} \mathrm{~F}\right)$ causes higher reaction barrier for $\operatorname{Ti}\left(\mathrm{a}^{3} \mathrm{~F}\right)$ systems. One difficulty may arise in the reactions of the excited states with $\mathrm{N}_{2} \mathrm{O}$. Since ground state of $\mathrm{N}_{2} \mathrm{O}$ correlates not with $\mathrm{N}_{2}\left({ }^{1} \Sigma\right)+\mathrm{O}\left({ }^{3} \mathrm{P}\right)$ but with $\mathrm{N}_{2}\left({ }^{1} \Sigma\right)+\mathrm{O}\left({ }^{1} \mathrm{D}\right)$, high spin excited states, $\mathrm{Ti}\left(\mathrm{a}^{5} \mathrm{~F}\right)$ and $\mathrm{V}\left(\mathrm{a}^{6} \mathrm{D}\right)$, can not form ground state $\mathrm{MO}, \mathrm{TiO}\left(\mathrm{X}^{3} \Delta\right)$ and $\mathrm{VO}\left({ }^{4} \Sigma\right)$, by simple abstraction of singlet oxygen atom. 
Another explanation is the electron transfer mechanism. As we mentioned in the introduction, the rate constant of this mechanism is determined by the ionization potential and electron affinity. According to eq (1), the rate constants are expected to have strong correlation with the effective ionization potentials, I.P.- $\mathrm{E}_{\mathrm{el}}$, for same reactant molecule. The rate constants are plotted as a function of the effective I.P. in Figure 4. This figure shows the strong correlation such that the metal atom of lower effective I.P. has larger rate constant in reactions with all reactant molecules. This result suggests that the electron transfer mechanism is important in the reaction of Ti and $\mathrm{V}$. Absolute values of rate constants for $\mathrm{Ti}\left(\mathrm{a}^{5} \mathrm{~F}\right)$ and $\mathrm{V}\left(\mathrm{a}^{6} \mathrm{D}\right)$ are of same order of magnitude as those expected from the electron transfer mechanism.

This mechanism can be modified to explain the inefficient reaction rate of ground state, i.e. the rate constants of ground states are orders of magnitude smaller than those expected from the electron transfer (ET) mechanism. The schematic potential curves are shown in Fig. 5, where two covalent curves and one ionic curve are shown. Usually, in the ET mechanism, the curve crossing takes place at longer distance than the repulsive wall of covalent curve. However, this may not be true for the transition metal atom reactions, especially in its ground electronic state. The fully

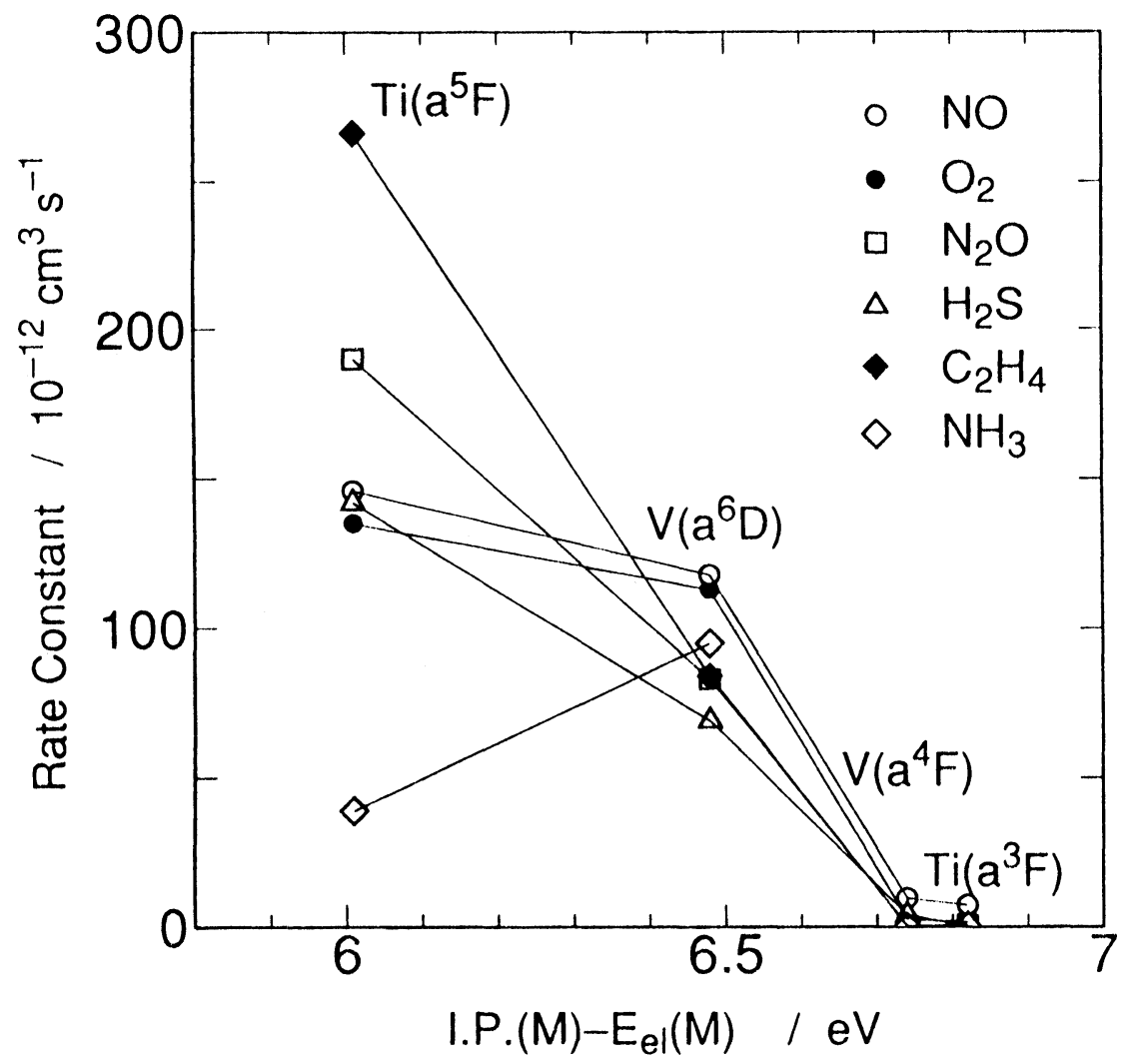

Figure 4 Plots of the rate constants vs the effective ionization potentials, I.P.(M)- $E_{\mathrm{el}}(M)$. 


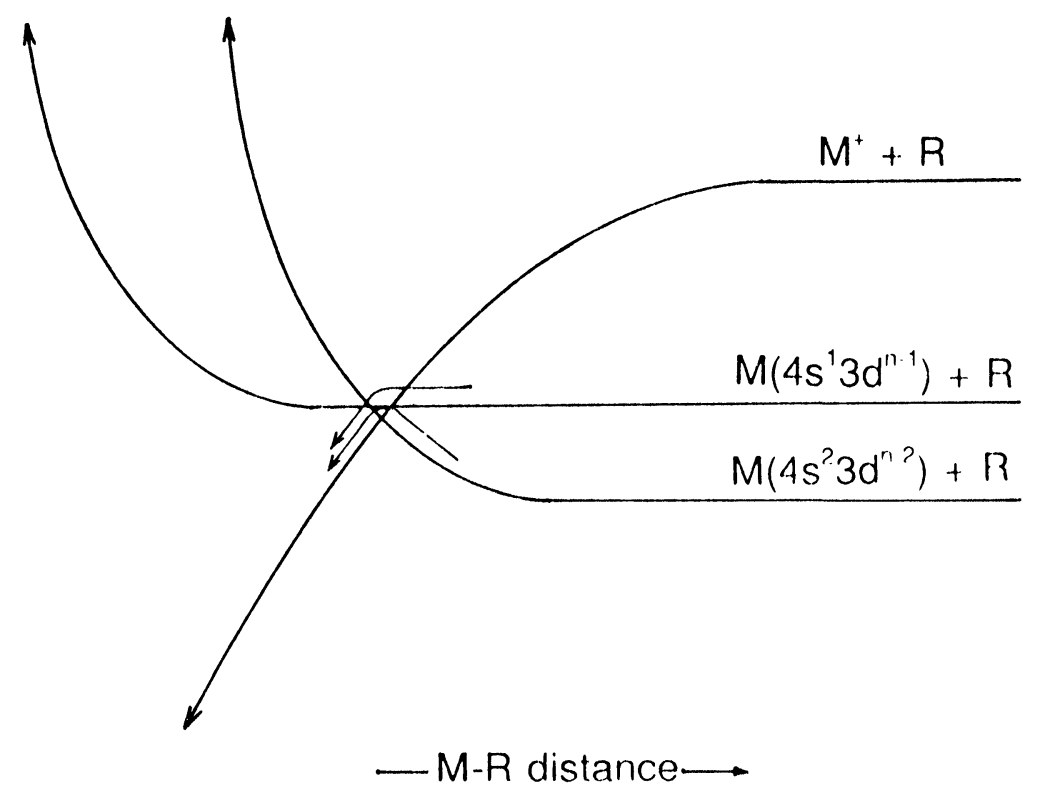

Figure 5 Qualitative potential energy curves showing the curve crossing between the ionic and covalent curves.

occupied $4 \mathrm{~s}$ orbital has large radius and the repulsive interaction may appear at longer distance than the curve crossing point. Diameters of $\mathrm{Ti}$ and $\mathrm{V}$ atoms are given as $4.00 \AA$ and $3.84 \AA$, respectively. ${ }^{29}$ By using these values and molecular diameters, hard-sphere radii are estimated to be around 3.6 to $4.1 \AA$ for molecules studied here. Since these are larger than $R_{x}$ 's given by eq (1), modification must be necessary to covalent curve evolved from the ground state metal atom-reactant pair, $M+R$, as shown in Fig. 5. If single occupation of $4 \mathrm{~s}$ orbital reduces the distance of repulsive wall, effect of repulsion on the curve crossing is minor in case of the excited state metal atom and reactant pair, $M^{*}+R$. It is clear from Figure 5 that the curve crossing between ionic surface and repulsive covalent surface provides an energy barrier. This energy barrier appears in $M+R$ adiabatic curve reducing the rate constants of the ground state metal atoms.

We may have to discuss about the correlation between the rate constants and the electron affinities of reactant molecules. According to eq (1), the rate constant must increase with increasing the electron affinity. However, neither our results nor others obtained previously show such correlation. This may not be unreasonable if we assume that the electron transfer mechanism works at entrance channel of the reaction and in the exit channel, dissociation of the intermediate, is controlled by other properties characteristic to the reactant pair. Also we have to notice that the reactions with ammonia do not fit with the electron transfer mechanism as shown in Fig. 4. This may not be surprising result since there are no known states of ammonia that can bind an electron. Thus, the electron transfer process cannot influence the ammonia system and therefore this reaction must proceed along neutral system. 


\section{SUMMARY}

We have determined the rate constants of gas-phase $\mathrm{Ti}$ and $\mathrm{V}$ atoms with some simple molecules by a discharge-flow tube method. The rate constants of first electronic excited states of both metal atoms have been determined as well as those of the ground state. In both metals and all reactant molecules, the electronic excited states show much larger rate than the ground states. The strong correlation between rate constants and the effective ionization potentials, IP(M)- $\mathrm{E}_{\mathrm{el}}$, has been seen in most of systems and suggests that the electron transfer mechanism plays an important role in the reactions of $\mathrm{Ti}$ and $\mathrm{V}$.

\section{References}

1. For example P. B. Armentrout and J. L. Beauchamp, Acc. Chem. Res. 22, 315 (1989).

2. M. L. Campbell and R. E. McClean, J. Phys. Chem. 97, 7942 (1993)

3. D. Ritter and J. C. Weishaar, J. Am. Chem. Soc. 112, 6426 (1990).

4. D. Ritter and J. C. Weishaar, J. Phys. Chem. 93, 1576 (1989)

5. D. Ritter and J. C. Weishaar, J. Phys. Chem. 94, 4907 (1990).

6. A. S. Narayan, P. M. Futerko, and A. Fontijn, J. Phys. Chem. 96, 290 (1992).

7. R. E. McClean and L. Pasternack, J. Phys. Chem. 96, 9828 (1992).

8. D. M. Manos and J. M. Parson, J. Chem. Phys. 63, 3575 (1975).

9. J. M. Parson, L. C. Geiger, and T. J. Conway, J. Chem. Phys. 74, 5595 (1981).

10. L. H. Dubois and J. L. Gole, J. Chem. Phys. 66, 779, (1977).

11. J. L. Gole and D. R. Preuss, J. Chem. Phys. 66, 3000 (1977).

12. D. Ritter, J. J. Carroll, and J. C. Weishaar, J. Phys. Chem. 96, 10636 (1992).

13. C. E. Brown, S. A. Mitchell, and P. A. Hackett, Chem. Phys. Lett. 191, 175 (1992).

14. S. A. Mitchell and P. A. Hackett J. Chem. Phys. 93, 7822 (1990).

15. M. A. Blitz, S. A. Mitchell, and P. A. Hackett, J. Phys. Chem. 95, 8719 (1991).

16. J. M. Parnis, S. A. Mitchell, and P. A. Hackett, J. Phys. Chem. 94, 8152 (1990).

17. D. E. Clemmer, K. Honma, and I. Koyano, J. Phys. Chem. 97, 11480 (1993).

18. K. Honma and D. E. Clemmer, to be submitted to J. Phys. Chem.

19. C. W. Bauschlicher, Jr. and S. R.Langhoff, J. Chem. Phys. 85, 5936 (1986).

20. C. W. Bauschlicher, P. S. Bagus, and C. J. Nelin, Chem. Phys. Lett. 101, 229 (1983).

21. R. D. Levine and R. B. Bernstein, Molecular Reaction Dynamics and Chemical Reactivity; Oxford University Press; New York, 1987.

22. The mean reaction time was determined by a time profile of emission from highly excited electronic states of Ti atom which were formed by a laser ablation. Detail is given in Ref. 18

23. Since the reactions of $\operatorname{Ti}\left(a^{5} F\right)$ and $V\left(a^{6} D\right)$ are efficient and occur by almost every collision with reactants, only collisional interconversion of J-levels with $\mathrm{He}$ could be faster than reactions.

24. Rate constants of $\operatorname{Ti}\left({ }^{3} \mathrm{~F}\right)$ and $\mathrm{V}\left(\mathrm{a}^{4} \mathrm{~F}\right)$ with $\mathrm{N}_{2} \mathrm{O}$ in our measurement show reverse order, i.e. $\mathrm{Ti}\left(\mathrm{a}^{3} \mathrm{~F}\right)$ $+\mathrm{N}_{2} \mathrm{O}>\mathrm{V}\left(\mathrm{a}^{4} \mathrm{~F}\right)+\mathrm{N}_{2} \mathrm{O}$. However, those determined by Ritter and Weishaar follow the order $\mathrm{V}<\mathrm{Ti}$. Therefore, we conclude that these two rate constants are almost identical.

25. This number is determined by using the $J$ averaged energies of $V\left(a^{4} F\right)$ and $V\left(a^{6} D\right)$.

26. K. P. Huber and G. Herzberg, Constants of Diatomic Molecules; van Nostrand Reinhold; 1979.

27. W. H. Breckenridge and H. Umemoto, Adv. Chem. Phys. 50, 325 (1982).

28. The LIF intensity of $\mathrm{V}\left(\mathrm{a}^{6} \mathrm{D}\right)$ is 0.4 of that of $\mathrm{V}\left(\mathrm{a}^{4} \mathrm{~F}\right)$. Since the transition probabilities for LIF absorption lines are $1.29 \times 10^{8} \mathrm{~s}^{-1}$ and $0.344 \times 10^{8} \mathrm{~s}^{-1}$ for $\mathrm{V}\left(\mathrm{a}^{6} \mathrm{D}\right)$ and $\mathrm{V}\left(\mathrm{a}^{4} \mathrm{~F}\right)$, respectively, the relative population of these states are estimated to be $11 \%$

29. C. F. Fischer, The Hartree-Fock Method for Atoms; Wiley; New York; 1977. 